\title{
Dinamika Pengembalian Pinjaman Koperasi: Perspektif Karakteristik Peminjam, Besarnya Pinjaman, Pendapatan Usaha dan Pengalaman Usaha
}

\author{
Sriyono $^{1 *}$, Oktavia Fajriati ${ }^{2)}$ \\ ${ }^{1 * 2)}$ Program Studi Manajemen, Universitas Muhammadiyah Sidoarjo \\ Jln. Mojopahit No. 666B, Sidoarjo, Jawa Timur, Indonesia, 61215 \\ E-mail: sriyono@umsida.ac.id ${ }^{\left.{ }^{*}\right)}$
}

\begin{abstract}
Masalah pengembalian pinjaman koperasi merupakan suatu bahasan yang menarik karena menentukan kelancaran dari berjalannya koperasi tersebut. Penelitian merupakan penelitian baru karena pembahasan yang dilakukan sangat lengkap. Penelitian ini bertujuan untuk mengetahui pengaruh karakteristik peminjam, besarnya pinjaman, pendapatan usaha dan pengalaman usaha terhadap pengembalian pinjaman koperasi pada Koperasi Simpan Pinjam dan Koperasi Serba Usaha di Kecamatan Candi, Kabupaten Sidoarjo. Penelitian ini termasuk jenis penelitian kuantitatif. Sampel yang digunakan pada penelitian ini sebanyak 150 responden pada Koperasi Simpan Pinjam dan Koperasi Serba Usaha di Kecamatan Candi, Kabupaten Sidoarjo. Teknik pengambilan sampel yang digunakan dalam penelitian ini adalah purposive sampling. Pengumpulan data dilakukan dengan penyebaran kuesioner. Metode penelitian untuk menguji kualitas data menggunakan uji validitas dan realibilitas. Sedangkan untuk analisis data menggunakan SEM (Structural Equation Modeling) dengan software AMOS 24. Hasil penelitian ini menunjukkan bahwa karakteristik peminjam, besar pinjaman, pendapatan usaha dan pengalaman usaha berpengaruh positif dan signifikan terhadap pengembalian pinjaman koperasi.
\end{abstract}

Kata kunci: Karakteristik Peminjam; Besar Pinjaman; Pendapatan Usaha; Pengalaman Usaha; Pengembalian Pinjaman

\begin{abstract}
The problem of repaying cooperative loans is an interesting discussion because it determines the smooth running of the cooperative. This research is a new research because the discussion carried out is very complete. This study aims to determine the effect of borrower characteristics, loan size, business income and business experience on cooperative loan repayment in savings and loan cooperatives and multipurpose cooperatives in Candi District, Sidoarjo Regency. This research is a type of quantitative research. The sample used in this study were 150 respondents in the savings and loans cooperative and multipurpose cooperative in Candi District, Sidoarjo Regency. The sampling technique used in this research is purposive sampling. Data was collected by distributing questionnaires. The research method to test the quality of the data using validity and reliability tests. Meanwhile, for data analysis using Structural Equation Modeling with AMOS 24 software. The results of this study indicate that the characteristics of the borrower, loan size, business income and business experience have a positive and significant impact on the loan repayment of cooperatives.
\end{abstract}

Keyword: Borrower Characteristics; Loan Size; Business Income; Business Experience; Loan Repayment 


\section{PENDAHULUAN}

Koperasi merupakan suatu lembaga keuangan non perbankan yang sangat diminati oleh masyarakat, karena keuntungan dari kegiatan tersebut dikembalikan lagi pada anggota koperasi. Dalam menyalurkan dananya, koperasi memberikan pinjaman kepada anggotanya untuk membiayai usaha para anggota. Pinjaman yang diberikan oleh koperasi sangat tidak memberatkan karena tidak diperlukan kolateral dan persyaratan yang lain, karena tidak memiliki syarat maka diharapkan peminjam dapat mengembalikan pinjaman dengan tepat waktu. Namun dalam pemberian pinjaman terdapat sebuah resiko. Resiko atas pemberian pinjaman yaitu terjadi ketidakpastian atau kegagalan peminjam untuk memenuhi kewajibannya. Berikut rasio pinjaman macet yang terjadi pada koperasi simpan pinjam dan koperasi serba usaha di Kecamatan Candi selama tahun 2019.

Tabel 1. Rasio Pinjaman Macet pada Koperasi Simpan Pinjam dan Serba Usaha di Kecamatan Candi Tahun 2019

\begin{tabular}{|c|c|c|c|c|c|}
\hline No & Koperasi & $\begin{array}{l}\text { Jumlah } \\
\text { Anggota } \\
\text { Koperasi }\end{array}$ & $\begin{array}{c}\text { Jumlah } \\
\text { Pinjaman } \\
\text { Yang } \\
\text { Diberikan }\end{array}$ & $\begin{array}{l}\text { Pinjaman } \\
\text { Yang } \\
\text { Macet }\end{array}$ & $\begin{array}{c}\text { Rasio } \\
\text { Pinjaman } \\
\text { Macet }(N P L)\end{array}$ \\
\hline 1 & $\begin{array}{l}\text { Koperasi Syariah Bueka } \\
\text { Ranting Sumorame }\end{array}$ & 52 & 122.500 .000 & 2.970 .000 & $2,42 \%$ \\
\hline 2 & KSPPS Darussalam & 23 & 47.000 .000 & 2.150 .000 & $4,57 \%$ \\
\hline 3 & KSPPS As Syifah & 67 & 148.000 .000 & 8.820 .000 & $5,96 \%$ \\
\hline 4 & $\begin{array}{l}\text { Koperasi Simpan Pinjam } \\
\text { Pembiayaan Syariah } \\
\text { Harapan Ummat Sidoarjo }\end{array}$ & 122 & 239.000 .000 & 4.720 .000 & $1,97 \%$ \\
\hline 5 & KSPPS Darunnisa & 41 & 103.000 .000 & 3.060 .000 & $2,97 \%$ \\
\hline 6 & $\begin{array}{l}\text { Koperasi Swamitra } \\
\text { Koppas Larangan }\end{array}$ & 87 & 193.500 .000 & 11.720 .000 & $6,06 \%$ \\
\hline 7 & $\begin{array}{l}\text { Koperasi Serba Usaha As } \\
\text { Sakinah }\end{array}$ & 859 & 1.481 .500 .000 & 58.590 .000 & $3,95 \%$ \\
\hline 8 & $\begin{array}{l}\text { Koperasi Serba Usaha } \\
\text { Tirto Sejahtera }\end{array}$ & 35 & 79.500 .000 & 1.000 .000 & $1,26 \%$ \\
\hline 9 & $\begin{array}{l}\text { Koperasi Serba Usaha } \\
\text { Aneka Usaha }\end{array}$ & 25 & 52.000 .000 & 3.000 .000 & $5,77 \%$ \\
\hline 10 & Koperasi Al Mubarok & 80 & 185.000 .000 & 1.500 .000 & $0,81 \%$ \\
\hline
\end{tabular}

Sumber: Dinas Koperasi dan Usaha Mikro Kabupaten Sidoarjo (2019)

Berdasarkan data tabel 1 , semakin rendah rasio pinjaman macet artinya semakin baik 
tingkat pengembalian pinjaman, begitupula sebaliknya semakin tinggi rasio pinjaman macet maka tingkat pengembalian pinjaman semakin buruk. Besarnya kasus penggantian kredit bermasalah tentunya dipengaruhi oleh variabel-variabel tertentu dari sisi nasabah (peminjam). Untuk miminimalisir resiko dalam pengembalian pinjaman koperasi maka perlu menganalisa karakteristik peminjam, besar pinjaman, pendapatan usaha serta pengalaman usahanya.

Fenomena masyarakat terhadap koperasi adalah suatu lembaga yang menyediakan fasilitas untuk dapat meminjam uang dan pengembaliaannya sangat fleksibel. Dari sisi lain pengurus koperasi mempunyai tanggung jawab bahwa semua pinjaman harus dikembalikan dengan tepat waktu. Karakteristik peminjam merupakan keseluruhan kelakuan dan kemampuan yang ada pada individu sebagai hasil dari pembawaan lingkungannya. Apabila karakteristik peminjam tidak baik seperti adanya debitur yang tidak jujur, awal tujuan meminjam dana untuk modal usaha, ternyata dana tersebut digunakan untuk memenuhi kebutuhan pribadinya, hal tersebut dapat menghambat pengembalian pinjaman (Robbins, et al., 2012).

Besarnya pinjaman adalah realisasi pinjaman yang diterima nasabah (dalam satuan ribuan) (Budi and Wirajaya, 2018). Besarnya jumlah pinjaman yang diberikan kepada pengusaha kecil yang menjadi mitra binaan maka akan meningkatkan produktifitas usaha yang dijalankannya (Asih, 2014). Tidak semua pinjaman yang diterima debitur digunakan untuk kegitan yang produktif, kebanyakan debitur pemanfaatan pinjamannya digunakan untuk pembelian konsumtif yang hanya untuk memenuhi keinginannya debitur dan keluarganya, apalagi kalau debitur tersebut terbentur dengan masalah kesulitan keuangan.

Pembayaran bisnis yang diterima oleh peminjam sangat persuasif pada penggantian kredit (Windariani dan Wirawati, 2017). Bayar akan mengukur seberapa besar kapasitas pemegang utang untuk memenuhi komitmennya terhadap yang menyenangkan. Penilaian ini sesuai dengan penelitian yang dipimpin oleh Nawai dan Shariff (2012) yang menyatakan bahwa semakin tinggi bayaran yang diperoleh, semakin tinggi peluang dan kecenderungan pemegang rekening untuk mengganti uang pinjaman dengan mudah. Namun unik dalam kaitannya dengan penelitian yang dipimpin oleh Rosiana (2015) yang menyatakan bahwa upah kerja tidak mempengaruhi penggantian kredit.

Pengalaman pertempuran adalah jangka waktu pemegang akun telah mempertahankan bisnisnya hingga saat ini (Marantika dan Sampurno, 2013). Semakin diperpanjang pemegang rekening mempertahankan bisnis, kesepakatan dan kemampuan orang yang berutang akan diasah bahkan dengan gangguan bisnis di seluruh dunia, sehingga tidak akan ada kesulitan dalam pengembalian kredit. Dengan demikian, semakin berlarut-larut pengalaman 
pertempuran orang yang berutang, semakin tinggi potensi pemegang rekening untuk mengembalikan kredit dengan mudah. Namun, karena pemeriksaan yang dipimpin oleh Marantika dan Sampurno (2013); Windariani dan Wirawati (2017) menyatakan bahwa pengalaman bisnis tidak berpengaruh pada uang pinjaman.

Tujuan dari penelitian ini adalah untuk memahami mengapa nasabah koperasi banyak yang mengalami hambatan saat mengembalikan pinjamannya. Penelitian ini sangat penting untuk dilakukan karena akan memberikan informasi mengapa banyak nasabah yang tidak mampu membayar pinjamannya. Hasil dari penelitian ini mempunyai kontribusi yang besar terhadap semua koperasi yang ada di Indonesia. Melalui hasil ini maka pengurus koperasi akan memahami langkah apa yang harus dilakukan agar para nasabah lancar dalam membayar pinjamannya.

Atribut adalah sifat atau watak seseorang. Pengurus koperasi harus memahami kepribadian peminjam yang akan datang jika peminjam adalah individu yang dapat diandalkan. Jika klien memiliki orang yang baik, itu mungkin akan mengembalikan kredit yang layak dan ada kemungkinan kecil untuk uang pinjaman yang buruk. Memahami tentang karakteristik dari nasabah dapat dilakukan beberapa cara, melalui survey, wawancara langsung maupun tidak langsung kepada orang-orang yang kenal dengan nasabah tersebut. Hubungan ini juga diperkuat oleh penelitian yang dipimpin oleh Widyartati (2016); Papias dan Ganesan (2019); dan Mpogole, et al (2015) yang hasil penelitiannya menunjukkan bahwa karakter klien memiliki hasil yang sangat menguntungkan pada pembayaran uang pinjaman. Pada penelitian tersebut bila karakter klien mempunyai latar belakang keuangan yang baik maka akan menguntungkan karena nasabah akan dapat mengembalikan pinjaman tepat waktu tapi sebaliknya bila karakter tersebut jelek.

Ukuran kredit adalah ukuran pengakuan di pinjaman yang diberikan oleh koperasi kepada klien. Jumlah kredit yang diperoleh klien akan digunakan untuk membangun bisnis, jumlah uang pinjaman yang diperoleh klien sangat penting karena melalui pinjaman ini akan meningkatkan bisnis klien, ini akan meningkatkan kelancaran pengembalian uang pinjaman yang dapat diterima. Besarnya ukuran kridet yang diberikan kepada nasabah sangat berhubungan dengan perjalanan bisnis nasabah. Nasabah meminjam digunakan untuk kegiatan produktif dalam kegiatan bisnisnya. Semakin besar jumlah kredit yang diberikan maka akan semakin lancer kegiatan usahanya. Bila kegiatan usahanya lancer maka nasabah akan sanggup membayar semua pinjamannya. Hubungan ini juga diperkuat oleh penelitian yang dipimpin oleh Asih (2014); Nawai dan Shariff (2012); dan Edet et al. (2016), hasil dari penelitian tersebut menunjukkan bahwa besarnya nilai pinjaman uang tersebut berpengaruh 
signifikan terhadap kelancaran pengembalian kredit. Semakin besar uang pinjaman maka semakin besar peningkatan hasil bisnis dari klien, dan akhirnya akan memudahkan untuk membayar pengembalian tersebut

Upah kerja adalah pendapatan yang akan diterima oleh pekerja, model pembayaran tersebut dapat diberikan dalam periode yang telah disepakati antara pekerja dan pemilik bisnis. Model pembayaran yang dilakukan oleh pemilik bisnis dapat berbeda-beda sesuai dengan kesepakatan, dapat ditentukan pada setiap minggu, setiap bulan atau setiap tahun. Upah yang diterima dari pemegang hutang digunakan untuk mengatasi masalah-masalahnya. Persyaratan pemegang hutang sangat tinggi dan berbeda salah satunya adalah memiliki upah yang besar. Oleh karena itu pemegang hutang membutuhkan banyak pembayaran untuk mengatasi masalahnya, dan untuk menangani bisnisnya. Dengan meningkatnya pembayaran bisnis, selama bisnis dijalankan, kemampuan untuk menangani bisnis meningkat dan kemampuan untuk membayar porsi dan biaya bunga meningkat, sehingga peluang untuk kelancaran pengembalian kredit juga lebih menonjol (Widayanthi, 2012). Hubungan ini juga diperkuat dengan penelitian yang oleh Arinta (2014); Windariani dan Wirawati (2017), dan Mokhtar dkk. (2012) yang menyatakan bahwa upah kerja berpengaruh positif terhadap kelancaran penggantian uang pinjaman. Ini berarti semakin besar upah dari nasabah maka semakin besar kemampuan dalam membayar pinjaman. Oleh karena itu pengurus koperasi harus seleksi dalam memilih nasabah yang berhutang meskipun nasabah tersebut adalah anggota koperasi

Pemeriksaan yang diarahkan oleh Arinda dan Maski (2015), menyatakan bahwa pengalaman bisnis adalah pergerakan waktu yang dihabiskan oleh para pelaku bisnis untuk mempertahankan bisnisnya dan menjalani pengalaman yang diperoleh selama mempertahankan bisnisnya. Pengalaman akan mempengaruhi kemampuan dalam menyelesaikan tugas serta membuat pekerjaan menjadi lebih efektif. Melalui pengalaman ini, seorang individu memahami kesalahan-kesalahan yang telah dibuat, dan mencari alasan munculnya kesalahan-kesalahan tersebut. Jadi untuk memutuskan untuk mengambil uang pinjaman, itu akan dipikirkan dengan hati-hati. Selanjutnya, semakin menarik pengalaman bisnis dan semakin menonjol kapasitas pemegang rekening untuk mengembalikan uang pinjaman, semakin tinggi pengalaman bisnis. Hubungan antara pengalaman bisnis dan penggantian uang pinjaman diperkuat oleh efek samping dari eksplorasi yang disutradarai oleh Wulandari (2019); Arinda dan Maski (2015); dan Ojiako, et al. (2014), yang menyatakan bahwa pengalaman bisnis memiliki dampak positif dan kritis terhadap kelancaran penggantian uang pinjaman. Artinya nasabah yang mempunyai pengalaman bisnis yang lama maka 
berpengaruh signifikan terhadap kemampuan dalam pembayaran utang.

\section{METODE PENELITIAN}

Rancangan dalam penelitian ini adalah rancangan explanatory research, yang menjelaskan hubungan sebab akibat antar variabel melalui pengujian hipotesis. Populasi dalam penelitian ini adalah koperasi di Kec. Candi, Kab. Sidoarjo yang telah teraftar di ODS (Online Data Sistem) Kementerian Koperasi dan Usaha Kecil dan Menengah Republik Indonesia (nik.depkop.go.id). Jumlah populasi yang digunakan sebanyak 15.742 anggota koperasi.

Teknik sampel penelitian ini menggunakan purposive sampling, dengan kriteria sebagai berikut:

Tabel 2. Kriteria Purposive Sampling

\begin{tabular}{clcc}
\hline No & \multicolumn{1}{c}{ Kriteria } & Jumlah & Total \\
\hline 1 & $\begin{array}{l}\text { Koperasi di Kec. Candi, Kab. Sidoarjo yang terdaftar } \\
\text { di Online Data Sistem (48 Koperasi) }\end{array}$ & 15.742 & 15.742 \\
2 & $\begin{array}{l}\text { Koperasi yang bukan kelompok Koperasi Simpan } \\
\text { Pinjam dan Koperasi Serba Usaha } \\
\text { (33 Koperasi) }\end{array}$ & $\begin{array}{l}(10.006) \\
\text { Penyebaran sampling sebanyak 10 pada setiap } \\
\text { koperasi. (15 Koperasi) }\end{array}$ & (5.586) \\
\hline
\end{tabular}

Sumber: Data yang diolah (2021)

Berdasarkan kriteria purposive sampling, maka diperoleh sebanyak 150 sampling yang memenuhi kriteria.

\section{Definisi Variabel, Indikator dan Skala Pengukuran}

Tabel 3. Definisi Variabel, Indikator dan Skala Pengukuran

\begin{tabular}{|c|c|c|c|c|}
\hline No & Nama Variabel & Definisi & Indikator & $\begin{array}{c}\text { Skala } \\
\text { Pengukuran } \\
\end{array}$ \\
\hline 1 & $\begin{array}{ll}\text { Karakteristik } & \\
\text { Peminjam } & \left(X_{1}\right) \\
\text { (Robbins, } & 2012) \\
(\text { Thoha, 2012) }\end{array}$ & $\begin{array}{l}\text { Merupakan tentang } \\
\text { kebiasaaan - kebiasaan, } \\
\text { sifat pribadi, cara hidup, } \\
\text { keadaan keluarga, hobby } \\
\text { dan keadaan sosial. }\end{array}$ & $\begin{array}{ll}\text { 1. } & \text { Sikap } \\
\text { 2. } & \text { Minat } \\
\text { 3. } & \text { Kebutuhan } \\
\text { 4. } & \text { Pengharapan } \\
\text { 5. } & \text { Kepercayaan }\end{array}$ & Interval \\
\hline 2 & $\begin{array}{l}\text { Besarnya Pinjaman } \\
\left(\mathrm{X}_{2}\right) \\
(\text { Suriya, 2012) }\end{array}$ & $\begin{array}{l}\text { Apakah atap atau ukuran } \\
\text { harta yang diberikan } \\
\text { koperasi } \\
\text { peminjam? }\end{array}$ & 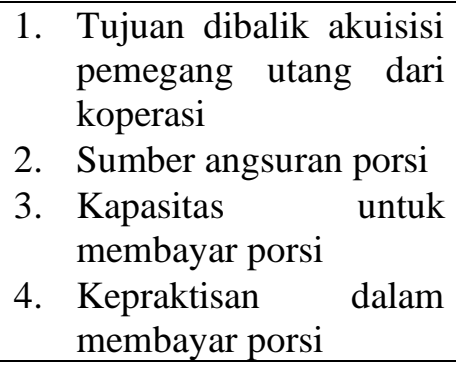 & Interval \\
\hline 3 & $\begin{array}{l}\text { Pendapatan } \\
\left(\mathrm{X}_{3}\right)\end{array}$ & $\begin{array}{lrr}\text { Apakah } & \text { hasil } & \text { yang } \\
\text { diperoleh } & \text { pemegang }\end{array}$ & $\begin{array}{l}\text { 1. Target perolehan } \\
\text { 2. Perolehan perolehan }\end{array}$ & Interval \\
\hline
\end{tabular}




\begin{tabular}{|c|c|c|c|c|}
\hline No & Nama Variabel & Definisi & Indikator & $\begin{array}{c}\text { Skala } \\
\text { Pengukuran }\end{array}$ \\
\hline & $\begin{array}{l}\text { (Abdurrahman, } \\
\text { 2010) }\end{array}$ & $\begin{array}{ll}\text { utang } & \text { dalam } \\
\text { mempertahankan } & \\
\text { usahanya saat ini. } & \end{array}$ & $\begin{array}{ll}\text { 3. Diutamakan } \\
\text { mengalokasi perolehan } \\
\text { 4. Distribusi pembayaran } \\
\text { untuk mengganti kredit } \\
\text { 5. Pembagian gaji untuk } \\
\text { mengatasi masalah }\end{array}$ & \\
\hline 4 & $\begin{array}{l}\text { Pengalaman Usaha } \\
\left(\mathrm{X}_{4}\right) \\
(\text { Abdurrahman, } \\
2010)\end{array}$ & $\begin{array}{lr}\text { Adalah waktu } & \text { yang } \\
\text { dihabiskan } & \text { oleh } \\
\text { penghibur bisnis } & \text { untuk } \\
\text { mempertahankan } & \text { bisnis } \\
\text { mereka dan } & \text { melalui } \\
\text { pengalaman } & \text { yang } \\
\text { diperoleh } & \text { selama } \\
\text { mempertahankan } & \text { bisnis } \\
\text { mereka. } & \end{array}$ & $\begin{array}{l}\text { 1. Kapasitas untuk } \\
\text { menciptakan bayaran } \\
\text { 2. Pengalaman sebelum } \\
\text { memulai bisnis } \\
\text { 3. Lama usaha } \\
\text { 4. Kapasitas untuk } \\
\text { mengawasi bisnis } \\
\text { 5. Kapasitas untuk } \\
\text { mengatasi masalah dan } \\
\text { keterampilan yang } \\
\text { dapat dibuktikan }\end{array}$ & Interval \\
\hline 5 & $\begin{array}{l}\text { Pengambalian } \\
\text { Pinjaman } \\
\text { (Yulianto, 2011) }\end{array}$ & $\begin{array}{l}\text { Adalah suatu keadaan } \\
\text { yang menunjukkan } \\
\text { kesanggupan pemegang } \\
\text { utang untuk mengganti } \\
\text { uang pinjaman yang } \\
\text { diberikan oleh yang } \\
\text { diperjanjikan. }\end{array}$ & $\begin{array}{l}\text { 1. Memahami komitmen } \\
\text { untuk membayar kredit } \\
\text { 2. Petunjuk langkah demi } \\
\text { langkah untuk } \\
\text { membayar porsi kredit } \\
\text { 3. Membayar kredit } \\
\text { sebelum pengembangan } \\
\text { 4. Melaporkan kondisi } \\
\text { apabila mengalami } \\
\text { penundaan pembayaran } \\
\text { 5. Keterlambatan } \\
\text { membayar pinjaman }\end{array}$ & Interval \\
\hline
\end{tabular}

Sumber: Data yang diolah (2021)

\section{Teknik Analisis}

Teknik analisis awal yang dilakukan adalah melakukan uji statistik deskriptif (Sugiyono, 2016). Kemudian dilanjutkan dengan uji kualitas data berupa uji validitas dan reliabilitas, uji kualitas sangat penting akan menentukan data yang dipakai apakah valid dan reliabilitas. Data dapat dikatakan valid apabila "Loading Factor" atau "Standardized Loading Estimate" > 0,05 (Ghozali, 2017). Jika nilai Construct Reliability > 0,70 maka variabel tersebut dikatakan reliabel (Ghozali, 2017).

Pada tahap selanjutnya dilakukan uji asumsi structure equation model meliputi uji normalitas, uji outliners dan uji multikolinieritas. Sebuah data dikatakan normal jika nilai critical ratio $<2,58$, sebaliknya jika nilai critical ratio $>2,58$ maka data tersebut berdistribusi tidak normal. Untuk uji outliners menggunakan pada tingkat $\mathrm{p}<0,001$. Terakhir dilakukan uji goodness of fit dengan kriteria sebagai berikut: 
Tabel 4. Goodness of Fit Index Table

\begin{tabular}{lc}
\hline \multicolumn{1}{c}{ Goodness of Fit Indexs } & Cut off Value \\
\hline Chi-Square & Diharapkan kecil \\
Significancy Probability & $\geq 0,05$ \\
RMSEA & $\leq 0,08$ \\
GFI & $\geq 0,90$ \\
AGFI & $\geq 0,90$ \\
CMIN/DF & $\leq 2,00$ \\
TLI & $\geq 0,90$ \\
CFI & $\geq 0,90$ \\
\hline
\end{tabular}

Sumber: Ghozali (2017)

Pengujian hipotesis dilakukan dengan menggunakan nilai $t$-value dengan tingkat signifikan 0,05. Nilai t-value dalam program AMOS terdapat pada tabel output Regression Weight. Apabila nilai probabilitas $(\mathrm{P}) \leq 0,05$ maka $\mathrm{H}_{0}$ ditolak dan hipotesis yang diteliti diterima.

\section{HASIL DAN PEMBAHASAN}

\section{Statistik Deskriptif}

Analisis deskriptif adalah salah satu dari bagian statistik yang digunakan. Skala distribusi kriteria pendapat adalah sebagai berikut:

$$
\begin{aligned}
& \text { Interval }=(\text { Nilai Maksimal }- \text { Nilai Minimal }) /(\text { Jumlah Kelas }) \\
& \text { Interval }=(5-1) / 5=0,8 \\
& \text { Sangat Rendah } \quad: 1,00-1,8 \\
& \text { Rendah } \quad: 1,81-2,6 \\
& \text { Cukup : } 2,61-3,4 \\
& \text { Tinggi : } 3,41-4,2 \\
& \text { Sangat Tinggi } \quad: 4,21-5
\end{aligned}
$$

\begin{tabular}{|c|c|c|c|c|c|c|c|c|c|}
\hline \multirow{2}{*}{ No } & \multirow{2}{*}{ Indikator } & \multicolumn{5}{|c|}{ Frekuensi Jawaban } & \multirow{2}{*}{$\mathbf{N}$} & \multirow{2}{*}{ Mean } & \multirow{2}{*}{ Kriteria } \\
\hline & & 1 & 2 & 3 & 4 & 5 & & & \\
\hline 1 & KP 1 & 9 & 4 & 20 & 60 & 57 & 150 & 4,01 & Tinggi \\
\hline 2 & $\mathrm{KP} 2$ & 10 & 10 & 12 & 55 & 63 & 150 & 4,01 & Tinggi \\
\hline 3 & KP 3 & 14 & 5 & 29 & 52 & 50 & 150 & 3,79 & Tinggi \\
\hline 4 & $\mathrm{KP} 4$ & 10 & 4 & 23 & 66 & 47 & 150 & 3,91 & Tinggi \\
\hline 5 & KP 5 & 14 & 6 & 35 & 44 & 51 & 150 & 3,75 & Tinggi \\
\hline 6 & $\mathrm{BP} 1$ & 17 & 6 & 24 & 52 & 51 & 150 & 3,76 & Tinggi \\
\hline 7 & $\mathrm{BP} 2$ & 4 & 7 & 26 & 45 & 68 & 150 & 4,11 & Tinggi \\
\hline 8 & BP3 & 8 & 4 & 23 & 72 & 43 & 150 & 3,92 & Tinggi \\
\hline 9 & BP4 & 12 & 9 & 38 & 51 & 40 & 150 & 3,65 & Tinggi \\
\hline
\end{tabular}

Tabel 5. Penilaian Responden terhadap Variabel 


\begin{tabular}{|c|c|c|c|c|c|c|c|c|c|}
\hline \multirow{2}{*}{ No } & \multirow{2}{*}{ Indikator } & \multicolumn{5}{|c|}{ Frekuensi Jawaban } & \multirow{2}{*}{$\mathbf{N}$} & \multirow{2}{*}{ Mean } & \multirow{2}{*}{ Kriteria } \\
\hline & & 1 & 2 & 3 & 4 & 5 & & & \\
\hline 10 & PDU1 & 12 & 10 & 42 & ב51 & 35 & 150 & ב3,58 & Tinggi \\
\hline 11 & PDU2 & 6 & 9 & 11 & 59 & 65 & 150 & 4,12 & Tinggi \\
\hline 12 & PDU3 & 5 & 4 & 29 & 56 & 56 & 150 & 4,03 & Tinggi \\
\hline 13 & PDU4 & 5 & 7 & 20 & 66 & 52 & 150 & 4,02 & Tinggi \\
\hline 14 & PDU5 & 7 & 4 & 21 & 57 & 61 & 150 & 4,07 & Tinggi \\
\hline 15 & PGU 1 & 11 & 3 & 19 & 46 & 71 & 150 & 4,09 & Tinggi \\
\hline 16 & PGU 2 & 11 & 5 & 23 & 50 & 61 & 150 & 3,97 & Tinggi \\
\hline 17 & PGU 3 & 19 & 5 & 18 & 57 & 51 & 150 & 3,77 & Tinggi \\
\hline 18 & PGU 4 & 12 & 0 & 24 & 64 & 50 & 150 & 3,93 & Tinggi \\
\hline 19 & PGU 5 & 8 & 0 & 23 & 54 & 65 & 150 & 4,12 & Tinggi \\
\hline 20 & PP 1 & 11 & 5 & 24 & 57 & 53 & 150 & 3,91 & Tinggi \\
\hline 21 & PP 2 & 11 & 17 & 29 & 37 & 56 & 150 & 3,73 & Tinggi \\
\hline 22 & PP 3 & 11 & 4 & 24 & 56 & 55 & 150 & 3,93 & Tinggi \\
\hline 23 & PP 4 & 9 & 4 & 17 & 67 & 53 & 150 & 4,01 & Tinggi \\
\hline 24 & PP 5 & 6 & 6 & 23 & 49 & 66 & 150 & 4,09 & Tinggi \\
\hline
\end{tabular}

Sumber: Data Primer (2021)

\section{Pengujian Kualitas Data}

\section{Uji Validitas}

Tabel 6. Hasil Uji Validitas

\begin{tabular}{lcllr}
\hline & & & Estimate \\
\hline KP5 & $\leftarrow$ & KP & 0,993 \\
KP4 & $\leftarrow$ & KP & 0,958 \\
KP3 & $\leftarrow$ & KP & 0,515 \\
KP2 & $\leftarrow$ & KP & 0,666 \\
KP1 & $\leftarrow$ & KP & 0,631 \\
BP4 & $\leftarrow$ & BP & 0,819 \\
BP3 & $\leftarrow$ & BP & 0,670 \\
BP2 & $\leftarrow$ & BP & 0,897 \\
BP1 & $\leftarrow$ & BP & 0,894 \\
PDU5 & $\leftarrow$ & PDU & 0,745 \\
PDU4 & $\leftarrow$ & PDU & 0,595 \\
PDU3 & $\leftarrow$ & PDU & 0,613 \\
PDU2 & $\leftarrow$ & PDU & 0,744 \\
PDU1 & $\leftarrow$ & PDU & 0,694 \\
PGU5 & $\leftarrow$ & PGU & 0,590 \\
PGU4 & $\leftarrow$ & PGU & 0,628 \\
PGU3 & $\leftarrow$ & PGU & 0,657 \\
PGU2 & $\leftarrow$ & PGU & 0,936 \\
PGU1 & $\leftarrow$ & PGU & 0,935 \\
PP1 & $\leftarrow$ & PP & 0,553 \\
PP2 & $\leftarrow$ & PP & 0,546 \\
PP3 & $\leftarrow$ & PP & 0,876 \\
PP4 & $\leftarrow$ & PP & 0,883 \\
PP5 & $\leftarrow$ & PP & 0,575 \\
Sumber: Output Data AMOS 24 (2021) &
\end{tabular}


Berdasarkan hasil analisis yang disajikan tabel 6 di atas seluruh indikator menunjukkan hasil yang baik dengan "Loading Factor" atau "Standardized Loading Estimate" > 0,05 sesuai dengan standart yang dikepinjamankan oleh Ghozali (2017). Maka kelima indikator tersebut sudah memenuhi validitas dan indikator tersebut dapat dipakai untuk analisis selanjutnya.

\section{Uji Reliabilitas}

Tabel 7. Hasil Uji Realibilitas

\begin{tabular}{lcc}
\hline \multicolumn{1}{c}{ Variabel } & Construct Reliability & Keterangan \\
\hline Karakteristik Peminjam & 0,835788378 & Reliabel \\
Besar Pinjaman & 0,883506179 & Reliabel \\
Pendapatan Usaha & 0,760809721 & Reliabel \\
Pengalaman Usaha & 0,855267166 & Reliabel \\
Pengembalian Pinjaman & 0,777073353 & Reliabel \\
\hline
\end{tabular}

Sumber: Output Data AMOS 24 (2021)

Berdasarkan tabel 7 nilai construct realiability dari uji realibilitas menunjukkan bahwa secara keseluruhan variabel dikatakan reliabel karena telah memenuhi persyaratan yang disyaratkan oleh (Ghozali, 2017) yaitu nilai construct realiability > 0,70. Dengan demikian penelitian ini dapat dilanjutkan untuk analisis selanjutnya.

\section{Uji Asumsi SEM}

\section{Analisis Model Struktural}

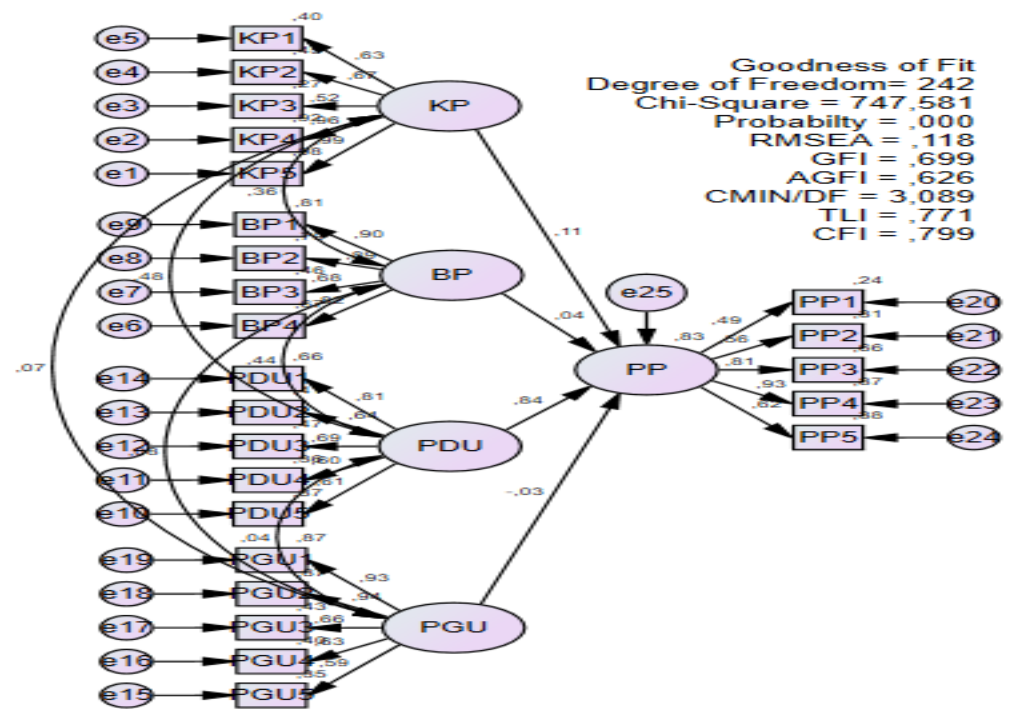

\section{Gambar 1. Analisis Full Model Awal}

Berdasarkan gambar 1 di atas dapat terlihat bahwa nilai uji kelayakan model (RMSEA, GFI, AGFI, CMIN/DF, TLI, dan CFI) belum menunjukkan model yang fit. 
Sehingga perlu melakukan modifikasi indek pada output AMOS. Berikut diagram jalur full model yang telah dimodifikasi dengan mengeliminasi indikator KP1, KP2, PDU 3, PDU 5, PGU4, PGU 5, PP 1 dan PP 5.

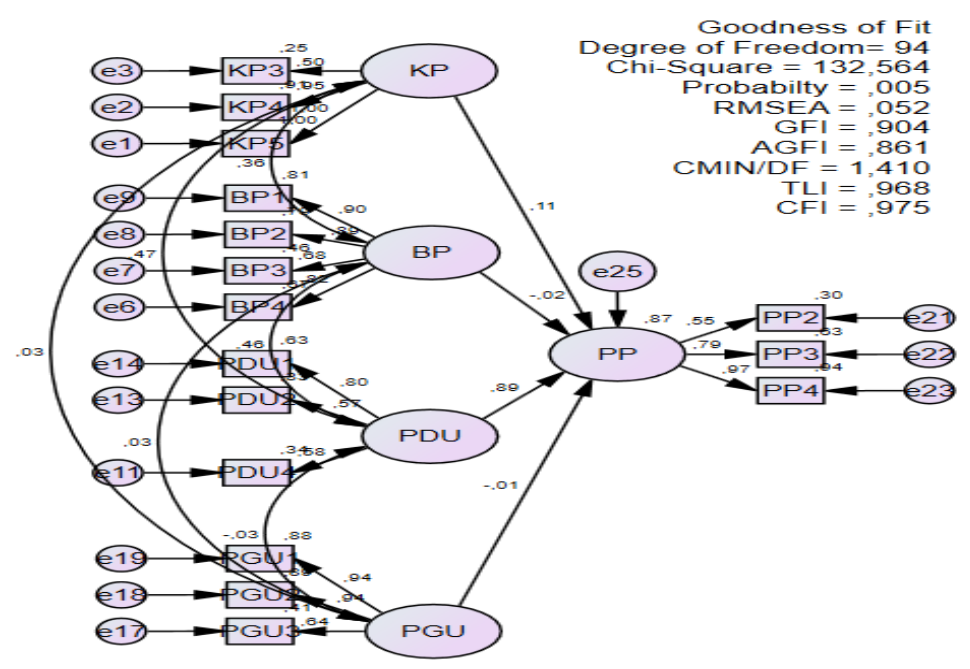

Gambar 2. Analisis Full Model Modifikasi

Setelah melakukan modifikasi,model tersebut sudah dapat dikatakan fit karena hasil dari RMSEA, GFI, CMIN/DF, TLI, dan CFI sesuai dengan kriteria Goodness of Fit Indexs menurut Ghozali (2017).

\section{Uji Normalitas}

Tabel 8. Assessment of Normality

\begin{tabular}{lrrrrrr}
\hline Variable & min & max & skew & c.r. & kurtosis & c.r. \\
\hline PP4 & 1,000 & 5,000 & $-1,301$ & $-6,504$ & 1,402 & 3,506 \\
PP3 & 1,000 & 5,000 &,- 843 & $-4,216$ &, 360 &, 900 \\
PP2 & 1,000 & 5,000 &,- 280 & $-1,399$ &,- 970 & $-2,426$ \\
PGU1 & 1,000 & 5,000 &,- 718 & $-3,590$ &,- 175 &,- 438 \\
PGU2 & 1,000 & 5,000 &,- 733 & $-3,665$ &,- 426 & $-1,064$ \\
PGU3 & 1,000 & 5,000 &,- 412 & $-2,062$ &,- 941 & $-2,352$ \\
PDU1 & 1,000 & 5,000 & $-1,445$ & $-7,226$ & 1,570 & 3,925 \\
PDU2 & 1,000 & 5,000 & $-1,201$ & $-6,007$ &, 818 & 2,045 \\
PDU4 & 1,000 & 5,000 & $-1,313$ & $-6,563$ & 1,431 & 3,578 \\
BP1 & 1,000 & 5,000 &,- 943 & $-4,714$ &, 834 & 2,084 \\
BP2 & 1,000 & 5,000 &,- 952 & $-4,758$ &, 699 & 1,747 \\
BP3 & 1,000 & 5,000 &,- 722 & $-3,611$ &,- 029 &,- 072 \\
BP4 & 1,000 & 5,000 & $-1,091$ & $-5,456$ &, 949 & 2,373 \\
KP3 & 1,000 & 5,000 &,- 910 & $-4,548$ &,- 392 &,- 979 \\
KP4 & 1,000 & 5,000 & $-1,542$ & $-7,709$ & 2,157 & 5,392 \\
KP5 & 1,000 & 5,000 & $-1,434$ & $-7,170$ & 2,053 & 5,133 \\
Multivariate & & & & & 61,149 & 15,602 \\
\hline
\end{tabular}

Sumber: Output Data AMOS 24 (2021) 
Berdasarkan hasil bootstrapping menunjukkan nilai $\mathrm{P}=0,199$ artinya nilai ini sesuai dengan yang dipersyaratkan yaitu $\mathrm{P}>0,05$. Sehingga penelitian ini masih layak untuk digunakan dan dapat dilakukan analisis selanjutnya.

\section{Uji Outliers}

Hasil uji pengolahan data outliers secara multivariate sebagai berikut:

Tabel 9. Evaluasi Multivariate Outliers Awal

\begin{tabular}{rrrr}
\hline \multicolumn{1}{c}{ Observation number } & Mahalanobis d-squared & p1 & p2 \\
\hline 69 & 50,633 & 0,000 & 0,003 \\
129 & 48,587 & 0,000 & 0,000 \\
9 & 46,962 & 0,000 & 0,000 \\
59 & 43,875 & 0,000 & 0,000 \\
61 & 43,477 & 0,000 & 0,000 \\
121 & 40,925 & 0,001 & 0,000 \\
$\ldots$ & $\ldots \ldots \ldots$ & $\ldots \ldots$ & $\ldots \ldots$ \\
\hline
\end{tabular}

Sumber: Output Data AMOS 24 (2021)

Berdasarkan tabel 9, maka nilai Mahalanobis yang melebihi atau 39,252 mengidentifikasikan adanya data multivariate outliers. Dengan demikian akan dilakukan pengujian ulang karna terdapat multivariate outliers yang terlihat pada observasi $(69,129,9$, 59, 61, 121). Maka 6 responden tersebut harus dikeluarkan.

Tabel 10. Evaluasi Multivariate Outliers Akhir

\begin{tabular}{rrrr}
\hline Observation number & Mahalanobis d-squared & p1 & p2 \\
\hline 58 & 36,825 & 0,002 & 0,004 \\
78 & 35,395 & 0,004 & 0,002 \\
82 & 34,174 & 0,005 & 0,001 \\
55 & 32,725 & 0,008 & 0,001 \\
21 & 30,099 & 0,017 & 0,014 \\
121 & 29,448 & 0,021 & 0,012 \\
83 & 29,366 & 0,022 & 0,004 \\
20 & 27,623 & 0,035 & 0,031 \\
108 & 27,437 & 0,037 & 0,018 \\
117 & 27,211 & 0,039 & 0,011 \\
135 & 26,473 & 0,048 & 0,021 \\
90 & 26,028 & 0,054 & 0,023 \\
$\ldots$. & $\ldots \ldots \ldots$ & $\ldots \ldots$. & $\ldots \ldots$ \\
\hline
\end{tabular}

Sumber: Output Data AMOS 24 (2021)

Hasil uji pada tabel 10 di atas terlihat nilai tertinggi terletak pada observasi ke 58 sebesar 36,825 yang nilainya dibawah 39,252. Maka dapat disimpulkan tidak terdapat adanya 
multivariate outliers dari data yang digunakan dalam penelitian ini, sehingga jumlah responden yang dapat digunakan untuk analisis sebanyak 144 data.

\section{Uji Multikolinearitas}

Tabel 11. Correlations

\begin{tabular}{cccc}
\hline & & & Estimate \\
\hline KP & $\leftrightarrow$ & BP &, 365 \\
$\mathrm{KP}$ & $\leftrightarrow$ & PDU &, 524 \\
$\mathrm{KP}$ & $\leftrightarrow$ & PGU &, 001 \\
$\mathrm{BP}$ & $\leftrightarrow$ & PDU &, 463 \\
$\mathrm{BP}$ & $\leftrightarrow$ & PGU &,- 002 \\
PDU & $\leftrightarrow$ & PGU &,- 077 \\
\hline \multicolumn{2}{l}{ Sumber: Output Data AMOS 24 (2021) }
\end{tabular}

Berdasarkan tabel 11 diatas, tidak terdapat angka yang melebihi 0,9, maka pengujian selanjutnya dapat dilakukan.

Evaluasi Kinerja Goodness of Fit

Tabel 12. Evaluasi Kriteria Goodness of Fit

\begin{tabular}{clccc}
\hline No & \multicolumn{1}{c}{$\begin{array}{c}\text { Goodness of Fit } \\
\text { Indexs }\end{array}$} & $\begin{array}{c}\text { Cut off Value } \\
\mathrm{df}=94, \mathrm{P}=5 \% \text { maka } \\
\chi 2=117,632\end{array}$ & $\begin{array}{c}\text { Hasil } \\
132,564\end{array}$ & Marginal \\
\hline 1 & Chi-square & $\geq 0,05$ & 0,005 & Marginal \\
\hline 2 & Probability & $\leq 0,08$ & 0,052 & Baik \\
\hline 3 & RMSEA & $\geq 0,90$ & 0,904 & Baik \\
\hline 4 & GFI & $\geq 0,90$ & 0,861 & Marginal \\
\hline 5 & AGFI & $\leq 2,00$ & 1,410 & Baik \\
\hline 6 & CMIN/DF & $\geq 0,90$ & 0,968 & Baik \\
\hline 7 & TLI & $\geq 0,90$ & 0,975 & Baik \\
\hline 8 & CFI & & & \\
\hline
\end{tabular}

Sumber: Data primer (2021)

Berdasarkan tabel 12 diatas hasil dari Chi-square yaitu 132,564 yang artinya hasil keseluruhan memenuhi kriteria fit.

\section{Uji Hipotesis}

Tabel 13. Hasil Uji Hipotesis

\begin{tabular}{ccccccc}
\hline \multicolumn{2}{l}{ Regression Weights: } & Estimate & S.E. & C.R. & P & Ket. \\
\hline $\mathrm{PP} \leftarrow$ & KP & 2,746 &, 520 & 5,283 &, 000 & Signifikan \\
$\mathrm{PP} \leftarrow$ & $\mathrm{BP}$ & 1,129 &, 526 & 2,146 &, 032 & Signifikan \\
$\mathrm{PP} \leftarrow$ & PDU & 1,446 &, 587 & 2,465 &, 014 & Signifikan \\
$\mathrm{PP} \leftarrow$ & $\mathrm{PGU}$ & 1,956 &, 523 & 1,986 &, 011 & Signifikan \\
\hline
\end{tabular}

Sumber: Output Data AMOS 24 (2021) 


\section{Pengaruh karakteristik peminjam terhadap pengembalian pinjaman}

$\mathrm{H}_{0}=$ kualitas peminjam tidak memiliki dampak penting pada penggantian uang pinjaman.

$\mathrm{H}_{1}=$ kualitas peminjam berpengaruh signifikan terhadap penggantian kredit.

Dilihat dari tabel after effect pengujian teori KP terhadap PP diperoleh P sebesar 0,000. Hal ini menunjukkan bahwa $0,000<0,05$. Oleh karena itu, $\mathrm{H}_{0}$ ditolak dan $\mathrm{H}_{1}$ diakui, yang menyiratkan bahwa atribut peminjam secara signifikan mempengaruhi penggantian kredit yang bermanfaat.

\section{Pengaruh besarnya pinjaman tehadap pengembalian pinjaman}

$\mathrm{H}_{0}=$ ukuran kredit tidak berdampak besar pada penggantian uang muka.

$\mathrm{H}_{2}=$ besarnya kredit berpengaruh signifikan terhadap uang muka.

Berdasarkan tabel hasil uji spekulasi BP terhadap PP diperoleh P sebesar 0,032. Hal ini menunjukkan bahwa $0,032<0,05$. Dengan cara ini $\mathrm{H}_{0}$ dihilangkan dan $\mathrm{H}_{1}$ diakui, yang menyiratkan bahwa ukuran kredit secara signifikan mempengaruhi penggantian uang muka yang disetujui.

\section{Pengaruh pendapatan usaha terhadap pengembalian pinjaman}

$\mathrm{H}_{0}=$ upah kerja tidak memiliki dampak kritis terhadap penggantian kredit.

$\mathrm{H}_{3}=$ upah kerja berpengaruh signifikan terhadap penggantian kredit.

Dilihat dari tabel konsekuensi uji teori PDU pada PP diperoleh P sebesar 0,014. Hal ini menunjukkan bahwa $0,014<0,05$. Dengan cara ini $\mathrm{H}_{0}$ dihilangkan dan $\mathrm{H}_{1}$ diakui, yang menyiratkan bahwa upah kerja secara signifikan mempengaruhi kedatangan uang muka yang dapat disetujui.

\section{Pengaruh pengalaman usaha terhadap pengembalian pinjaman}

$\mathrm{H}_{0}=$ pengalaman bisnis tidak memiliki dampak penting pada penggantian uang muka.

$\mathrm{H}_{4}=$ pengalaman bisnis berpengaruh signifikan terhadap penggantian kredit.

Dilihat dari tabel hasil uji teori PGU terhadap PP didapatkan P sebesar 0,011. Hal ini menunjukkan bahwa 0,011 < 0,05. Oleh karena itu, $\mathrm{H}_{0}$ ditolak dan $\mathrm{H}_{1}$ diakui, yang menyiratkan bahwa pengalaman bisnis secara signifikan mempengaruhi kedatangan uang muka yang disetujui.

\section{Pembahasan}

1. Karakteristik Peminjam Berpengaruh Secara Signifikan terhadap Pengembalian Pinjaman

Berdasarkan tabel 13 menunjukkan bahwa atribut peminjam memiliki hasil yang besar dan konstruktif pada penggantian kredit bermanfaat. Konsekuensi dari pemeriksaan ini 
sesuai dengan penelitian yang dipimpin oleh Widyartati (2016) dan Mpogole, et al. (2012) yang menyatakan bahwa atribut peminjam berpengaruh signifikan terhadap penggantian kredit. Namun, efek samping dari penyelidikan ini tidak sesuai dengan Bob et al. (2018) dan Gustavo et al. (2017) yang menyatakan bahwa kualitas peminjam tidak berdampak pada penggantian uang pinjaman.

Dengan demikian dapat dinyatakan bahwa semakin baik karakteristik peminjam maka tingkat kelancaran pengembalian pinjaman koperasi akan semakin baik. Begitupula sebaliknya semakin buruk karakteristik peminjam maka tingkat kelancaran pengembalian pinjaman koperasi akan terhambat atau macet. Maka untuk meminimalisir resiko pengembalian pinjaman, koperasi perlu menganalisis karakteristik peminjam yang meliputi beberapa aspek yaitu kebutuhan, pengharapan dan kepercayaan.

\section{Besarnya Pinjaman Berpengaruh Secara Signifikan terhadap Pengembalian}

\section{Pinjaman}

Tabel 13 menunjukkan bahwa besarnya uang pinjaman memiliki hasil yang kritis dan konstruktif pada penggantian kredit yang bermanfaat. Penyelidikan ini sesuai dengan penelitian yang dipimpin oleh Ibeleme et al. (2013) serta Budi and Wirajaya (2018) yang menyatakan bahwa besar kecilnya uang pinjaman mempengaruhi kelancaran pengembalian kredit. Namun konsekuensi dari pemeriksaan ini tidak sesuai dengan Afriyeni (2013) yang menyatakan bahwa besarnya kredit tidak berdampak pada uang pinjaman.

Selanjutnya, cenderung diungkapkan bahwa semakin menonjol uang pinjaman yang diperoleh klien, semakin baik kecepatan pengembalian uang pinjaman yang disepakati. Karena besarnya kredit dapat dimanfaatkan oleh klien untuk menumbuhkan kemanfaatan dalam mempertahankan usahanya. Dengan peningkatan kegunaan, itu akan memperluas pembayaran klien dan akan membangun kesempurnaan penggantian kredit.

\section{Pendapatan Usaha Berpengaruh Secara Signifikan terhadap Pengembalian}

\section{Pinjaman}

Efek lanjutan dari pemeriksaan informasi menunjukkan bahwa upah kerja memiliki hasil yang besar dan konstruktif pada penggantian kredit yang layak. Penelitian ini memiliki kesamaan dengan penelitian yang dipimpin oleh Budi and Wirajaya (2018); Windariani dan Wirawati (2017); serta Nawai dan Shariff (2012) yang menyatakan bahwa semakin tinggi pembayaran bisnis, semakin baik kelancaran pembayaran uang pinjaman. Namun, efek samping dari penyelidikan ini tidak sesuai dengan Ramanujam dan Vidya (2017) Rosiana (2015) yang menyatakan bahwa upah kerja tidak berdampak pada penggantian 
uang pinjaman.

Dengan demikian apabila target pendapatan nasabah atas perolehan pendapatan sudah tercapai, maka nasabah dapat mengalokasikan sebagian pendapatannya untuk mengembalikan pinjaman koperasi. Semakin tinggi pendapatan usaha maka kemampuan nasabah untuk mengembalikan pinjaman semakin tinggi.

\section{Pengalaman Usaha Berpengaruh Secara Signifikan terhadap Pengembalian}

\section{Pinjaman}

Efek lanjutan dari pemeriksaan informasi menunjukkan bahwa pengalaman bisnis memiliki hasil yang besar dan konstruktif pada penggantian uang pinjaman yang disetujui. Penyelidikan ini sesuai dengan penelitian yang dipimpin oleh Wulandari (2019); Manuba dan Djinar (2019); serta Makorere (2014) yang menyatakan bahwa pengalaman bisnis memiliki dampak positif dan besar terhadap kelancaran penggantian uang pinjaman. Namun konsekuensi dari pemeriksaan ini tidak sesuai dengan Windariani dan Wirawati (2017) yang menyatakan bahwa pengalaman bisnis tidak berdampak pada uang pinjaman.

Dengan adanya pengalaman sebelum memulai usaha, nasabah memiliki ilmu dan pengetahuan dalam mengelola usahanya, dan apabila nasabah telah mengalami siklus lamanya usaha yang berjalan, maka nasabah dapat memiliki kemampuan dalam menghasilkan pendapatan yang lebih untuk mengembalikan pinjaman koperasi. Dengan demikian dapat dinyatakan bahwa semakin banyak nasabah yang memiliki pengalaman usaha maka tingat kelancaran pengembalian pinjaman akan semakin baik.

\section{KESIMPULAN}

Keberangsungan dari aktifitas koperasi sangat bergantung dari kelancaran pengembalian dari pinjaman yang dilakukan oleh anggota koperasi, berdasarkan hasil analisis maka kelancaran dari pengembalian pinjaman koperasi tergantung pada beberapa faktor diantaranya karakteristik peminjam, besarnya pinjaman, pendapatan usaha, pengalaman usaha.

\section{IMPLIKASI}

Implikasi penelitian ini bagi koperasi dan nasabah koperasi sangat besar. Bagi koperasi hasil dari peneltian ini memberikan informasi agar kredit yang diberikan pada nasabah tidak macet maka tindakan apa yang harus dipahami sudah jelas berdasarkan hasil penelitian ini yaitu karakteristik peminjam, besarnya pinjaman, pendapatan usaha, pengalaman usaha. Bagi nasabah agar pengajuan kreditnya disetujui oleh koperasi maka nasabah harus karekteristik 
yang baik, pinjaman yang digunakan harus digunakan sesuai dengan kegunaannya, pendapatan usaha yang diperoleh harus dikelola dengan baik serta pengalaman pengelolaan bisnis yang dimiliki digunakan sebagai evaluasi kegiatan bisnisnya.

\section{REFERENSI}

Abdurrahman, M. (2015). Memajukan Pengentasan Kemiskinan yang Efektif dan Pembangunan Pedesaan di Indonesia melalui Kebijakan Mikro dan Macra: Perspektif Sosiologis. Journal of Economics and International Finance, 16(2), 66-72.

Afriyeni. (2013). Elemen-Elemen yang Mempengaruhi Pengembalian Kredit Usaha Rakyat (KUR) pada PT. Bank Rakyat Indonesia (BRI) Unit Talang Cabang Solok. Jurnal Ilmiah Keuangan dan Perbankan, 6(2), 207-222.

Arinda, N. dan Maski, G. (2015). Penelitian Pengaruh Umur, Jumlah Tanggungan Keluarga, Pengalaman Usaha, Perputaran Usaha dan Jumlah Pinjaman terhadap Tingkat Pelunasan Kredit oleh UMKM Studi Kasus: BPR (BPR) Gunung Ringgit Malang. Jurnal Ilmiah Mahasiswa Fakultas Ekonomi dan Bisnis: Universitas Brawijaya, 3(2), hlm. 1-12.

Arinta, DY. (2014). Pengaruh Karakteristik Individu, Karakteristik Usaha, Karakteristik Kredit terhadap Kemampuan Debitur Membayar Kredit pada BPR Jatim Cabang Probolinggo. Jurnal Ilmiah Mahasiswa Fakultas Ekonomika dan Bisnis: Universitas Brawijaya, 2(1), 1-16.

Asih, M. (2014). Pemeriksaan Faktor-Faktor yang Mempengaruhi Pengembalian Kredit Pengusaha Kecil dalam Program Kemitraan Tanggung Jawab Sosial Perusahaan (Studi Kasus: PT Telkom Drive II Jakarta). Manajemen Jurnal, 5(1), 73-94.

Budi, L. A. D. and Wirajaya, I. G. A. (2018). The Influence of Dependents, Operating Income, and Loan Size on the Smooth Rate of Credit Repayment, E-Jurnal Accounting, 24(2), 1077-1104.

Edet, O. dst. (2016). Investigasi Peminjaman dan Pelunasan Kredit di antara Peternak Ternak di Negara Bagian Cross River, Nigeria. Global Journal of Pure and Applied Sciences, 2(1), 33-40.

Ghozali, I. (2017). Konsep dan Aplikasi Model Persamaan Struktural dengan Program AMOS 24. Semarang: Badan Penerbit Universitas Diponegoro.

Gustavo, A.et al. (2017). Kontribusi Empirik Perilaku Kecemasan Konsumen pada dan dalam Pelunasan Kartu Kredit. Manajemen Kartu Biaya dan Literasi Keuangan di Antara Mahasiswa. Jurnal Manajemen Keuangan, Pasar dan Institusi, 5(1).

Ibeleme dkk. (2013). Penentu Ukuran Pinjaman dan Kinerja Pelunasan Produsen Minyak Kecil di Negeria: Studi Perawatan Negara Bagian Abia. Jurnal Internasional Manajemen dan Administrasi Bisnis, 2(3), 43-54.

Makorere, R. F. (2014). Komponen yang Mempengaruhi Pelaksanaan Penggantian Uang Pinjaman di Tanzania: Bukti Empiris dari Distrik Dar Es Salaam dan Morogoro. International Journal of Development and Sustainability, 3(3), 481-492.

Manuba, I. dan Djinar, N. (2019). Pengaruh Karakter, Kapasitas, Modal, Agunan, Kondisi Ekonomi dan Hambatan terhadap Keputusan Pemberian Kredit. International Journal of Science a Research (IJSR), 8(2), 278-281. 
Marantika, C. R. dan, Sampurno, R. D. (2013). Investigasi Faktor Mikro yang Mempengaruhi. Jurnal Manajemen Dipenogoro, 2(2), 1-14.

Mokhtar, S.H. dkk. (2012). Penentu Masalah Penggantian Uang Pinjaman Kredit Mikro di Antara Peminjam Keuangan Mikro di Malaysia. 2(7), 33-45.

Mpogole, BH, Mwaungulu, I. dan Mlasu, S. (2012). Banyak Pinjaman dan Pelunasan Pinjaman: Sebuah Studi Klien Keuangan Mikro di Iringa, Tanzani. Jurnal Global Manajemen dan Riset Bisnis, 12(4). 1-7.

Naawai, N. dan Shariff, M. N. M. (2012). Variabel yang Mempengaruhi Kinerja Pembayaran Kembali dalam Program Keuangan Mikro di Malaysia. Procedia - Ilmu Sosial dan Perilaku, 62, 806-811.

ODS (Online Data System) Kementerian Koperasi dan Usaha Kecil Menengah Republik Indonesia. (2020). Dapat diakses di: nik.depkop.go.id. [Diakses, 18 April 2020]. 
P-ISSN : 2252-844X 